\title{
QUÍMICXS NEGROS E NEGRAS DO SÉCULO XX E O RACISMO INSTITUCIONAL NAS CIÊNCIAS
}

\author{
Arlene Santos Silva ${ }^{1}$ \\ Bárbara Carine Soares Pinheiro²
}

\section{RESUMO}

O presente trabalho traz a trajetória de alguns cientistas negros e negras da área química que atuaram durante o Século XX, contrapondo as políticas separatistas de seus tempos. As atuações destes e destas cientistas serviram de exemplo de luta e resistência, além de contribuírem para a ampliação do legado afrodescendente no âmbito técnico e científico da humanidade. A análise das trajetórias desses cientistas foi feita sob a perspectiva do reflexo do racismo e racismo institucional no desenvolvimento de seus trabalhos e carreiras acadêmica e profissional. A partir deste estudo foi percebida a necessidade de reafirmar a imagem da população negra como uma população intelectualmente produtiva, redirecionando a centralidade da evolução e desenvolvimento tecnológico e científico de modo a mostrar a real face do desenvolvimento, plural, no que tange à etnia e gênero dos e das cientistas e produtores de tecnologias e conhecimentos pelo mundo.

Palavras-chave: Racismo institucional. Cientistas negros e negras. Relações étnicoraciais nas ciências.

\section{BLACK CHEMISTRY OF THE 20TH CENTURY AND INSTITUTIONAL RACISM IN THE SCIENCES}

\begin{abstract}
The present work presents the trajectory of black chemical scientists who acted during the 20th century, opposing the separatist politics of their time. The actions of these scientists served as examples of struggle and resistance, as well as contributions to the expansion of the Afrodescendant legacy in the technical and scientific sphere of humanity. The analysis of the trajectories of these scientists was made under the perspective of the reflection of racism and institutional racism in the

\footnotetext{
1 Licenciada e bacharel em química pela Universidade Federal da Bahia. Doutoranda em química pela UFBA. Orcid iD: https://orcid.org/0000-0001-6899-8485. E-mail: arlene.ufba@gmail.com

2 Professora adjunta II do Instituto de Química da Universidade Federal da Bahia licenciada em química, mestre e doutora em ensino, filosofia e história das ciências UFBA/UEFS. Orcid iD: https://orcid.org/0000-0002-2766-1349.E-mail: soarespinheirob@gmail.com
} 
development of their work and academic and professional careers. The results of this study indicate the need to reaffirm the image of the black population as an intellectually productive population, redirecting the centrality of evolution and technological and scientific development in order to show the real face of development, plural, regarding ethnicity and gender of scientists and producers of technologies and knowledge around the world.

Keywords: Institutional Racism. Black scientists. Ethnic-racial relations in the sciences.

\section{QUÍMICXS NEGROS Y NEGRAS DEL SIGLO XX Y EL RACISMO INSTITUCIONAL EN LAS CIENCIAS}

\section{RESUMEN}

El presente trabajo trae la trayectoria de algunos científicos negros y negras del área de la química que actuaron durante el Siglo XX, contraponiendo las políticas separatistas de sus tiempos. Las actuaciones de estos y de estas científicas sirvieron de ejemplo de lucha y resistencia. Además de contribuir a la ampliación del legado afrodescendente en el ámbito técnico y científico de la humanidad. El análisis de las trayectorias de estos científicos se hizo bajo la perspectiva del reflejo del racismo y el racismo institucional en el desarrollo de sus trabajos y carreras académica y professional. A partir de este estudio se percibió la necesidad de reafirmar la imagem de la población negra como una población intelectualmente productiva, redirecionando la centralidad de la evolución y desarrolho tecnológico y científico para mostrar la real cara del desarrollo, plural, en lo que se refiere a la etnia y genero de los y de las científicos produtores de tecnologías y conocimentos del mundo.

Palabras clave: Racismo institucional. Científicos negros y negras. Relaciones étnicoraciales em las ciências.

\section{INTRODUÇÃO}

O Brasil é um país de dimensão continental e rico em diversidades de cores, de gêneros, de etnias, de bens naturais, materiais e imateriais. No entanto, no que tange à diversidade de etnias, carrega o estigma da discriminação e segregação com base no conceito de raça, o racismo. Contudo, a prática deste modelo de discriminação não nasceu dentro das conjunturas, social e política, brasileiras. De acordo com a pesquisadora Lia Schucman, o racismo, enquanto fenômeno, apresenta localização histórica e social, sendo empregado inicialmente para justificar os processos de expansão da comunidade europeia pelo mundo baseada na escravização dos povos africanos, na colonização, na expansão do capitalismo e, no 
extermínio dos judeus a partir da ideia de pureza racial durante a segunda guerra mundial, resultando na hierarquização dos europeus com relação às demais populações (SCHUCMAN, 2010).

De acordo com a literatura, o racismo pode ser entendido como uma construção ideológica iniciada a partir do contato dos europeus com populações de outros continentes - Século XVI, período das grandes navegações. O ideário de valores criado por eles, baseados nos progressos da biologia, antropologia e linguística da época, consolidou cientificamente o conceito de raça amplamente utilizado a partir do século XIX.

No entanto, ao se observar as relações sociais atuais, pode-se perceber que a ideia de raça superior não mais rege e direciona os discursos e práticas discriminatórias. Ainda que o colorismo, ou pigmentocracia, seja o cerne de muitas manifestações relacionadas à prática de atos de discriminação e injurias raciais. O colorismo refere-se ao sistema de hierarquização dos sujeitos com base na cor mais clara ou mais escura cuja consequência é a concessão de "privilégios" aos indivíduos com a cor da pele mais clara, em detrimento dos indivíduos com a cor da pele mais escura, no que toca às oportunidades de mobilidade social (NASCIMENTO, 2015). Já a injúria racial, refere-se à injúria preconceituosa, e está enquadrada no código penal brasileiro como crime, com pena de reclusão que pode variar de um a três anos e multa, quando o autor, fundado na raça, cor ou etnia, ofende a honra subjetiva da vítima.

Deste modo, o racismo perde seu alicerce biologizante e passa a ser definido enquanto processo de construção social. Este fato justifica a permanência desta prática, contrariamente ao que se deveria esperar, o seu desaparecimento, uma vez que, foram comprovadas a inexistência de marcadores biológicos que diferenciassem os seres humanos em raças biológicas, ainda que originários de diferentes etnias (SCHUCMAN, 2010). Assim, o racismo passa a ser definido considerando a perspectiva de constructo social, político, ideológico e cultural. E o conceito de raça passa a ser adotado enquanto "raça social", a partir do qual, de acordo com Kajibanga (2014, p. 61), racismo "é um conjunto de estereótipos, 
preconceitos e discriminações que se baseia na crença da superioridade/inferioridade de um grupo racial ou étnico com relação a outro, em uma conjuntura de dominância social".

Segundo Silvio Almeida (2018), professor de filosofia do direito, o racismo é dividido, e praticado, de três diferentes formas: racismo estrutural, racismo institucional e racismo de estado. Racismo estrutural se refere ao racismo como uma ação "normal" uma vez que constitui as relações sociais de maneira racional como modo de estrutura social, normalizado nas relações políticas e econômicas; o racismo institucional se refere à não miscigenação em espaços de poder e nas instituições públicas e privadas em geral; e racismo de estado se refere à falta de políticas públicas por parte do estado com o objetivo de inibir as práticas discriminatórias e, deste modo, promover a ocupação de espaços de poder por pessoas negras, bem como, desestruturar as relações baseadas em discriminações raciais. Com base nestas definições, o racismo é considerado todo processo que coloca o negro em posição de inferioridade. Isso, possibilita compreender o fundamento dos movimentos afirmativos e da luta em prol das políticas de reparação voltadas para a promoção de equidade da população negra no país.

A relação racial no ambiente acadêmico e científico não difere das relações existentes na sociedade. Uma vez que, os profissionais negros são muitas vezes desvalorizados, quando não invisibilizados. Assim, se faz necessário um processo de desconstrução desse ideário. Esse processo passa pelo reconhecimento das produções científicas desenvolvidas por pesquisadores e pesquisadoras africanas e afrodescendentes. Além disso, seus feitos devem ser creditados e valorizados, de modo a corrigir os erros cometidos durante o processo de colonização dos povos negros africanos. A partir do qual toda a historicidade e contribuições científicas oriundas da África foram, secularmente, ocultadas (MACHADO; LORAS, 2014).

Diante disso, este trabalho tem como objetivo apresentar uma narrativa biográfica da carreira acadêmica e científica de alguns químicxs negros e negras, do Século XX, com base na análise do livro Ciência, 
Tecnologia e Inovação Africana e Afrodescendente, do autor Carlos Machado, bem como em bases de dados da Internet. Os dados foram interpretados a partir da discussão sobre como o racismo institucional pode ter influenciado na ocultação da divulgação de suas contribuições no que tange à história das ciências, discutindo racismo e racismo institucional nas trajetórias desses cientistas.

\section{RACISMO INSTITUCIONAL}

De acordo com Almeida (2018), racismo estrutural é algo enraizado nas bases das relações sociais, sendo estrutural e estruturante da mesma. Não está relacionado à falta de caráter ou à ignorância, não é direto, e nem violento (pelo menos aparentemente), mas ao contrário, é sutil, natural, um hábito cotidiano e corriqueiro, pois opera dentro da normalidade das estruturas das relações sociais: a econômica, a política e a subjetiva. E é esta normalidade naturalizante do racismo estrutural que nos impede de percebê-lo, para então questionar e desenvolver mecanismos que possam ir contra a continuidade dos privilégios de um grupo em detrimento ao outro. A partir dessa base racista estrutural se assentam as diferentes manifestações de opressões de raça, vivenciadas nos diferentes segmentos da nossa sociedade, como por exemplo o racismo religioso e o racismo institucional.

Segundo Almeida (2018), racismo institucional é qualquer sistema de desigualdade que se baseia em raçaque pode ocorrer em instituições como órgãos públicos governamentais, corporações empresariais privadas e universidades (públicas ou privadas). $O$ termo foi introduzido pelos ativistas Stokely Carmichael e Charles V. Hamilton do movimento Black Power no final de 1960, nos Estados Unidos. A definição dada por William Macpherson em seu relatório sobre o assassinato de Stephen Lawrence é "o fracasso coletivo de uma organização em fornecer um serviço adequado e profissional às pessoas por causa de sua cor, cultura ou origem étnica". A força do racismo institucional está em capturar as maneiras pelas quais sociedades inteiras, ou seções delas, são afetadas pelo racismo, ou talvez por legados racistas, muito tempo depois dos indivíduos racistas terem desaparecido. 
Segundo Pace e Lima (2011), os objetivos da criação do conceito de racismo institucional eram de especificar como se manifesta o racismo nas estruturas da organização da sociedade e nas instituições, para descrever os interesses, ações e mecanismos de exclusão estabelecidos pelos grupos racialmente dominantes.

É importante ressaltar que no Brasil o racismo teve suas raízes na escravidão - a qual durou mais de três séculos -, sendo um dos últimos países do mundo a abolir essa prática. Mesmo após a abolição da escravidão, mediante a assinatura da Lei Áurea em 13 de maio de 1888, a população negra permaneceu marginalizada e com o acesso ao trabalho distribuído de forma desigual, cabendo a esse segmento, na maior parte das vezes, a ocupação de posições subalternas. Tem-se uma construção do racismo de forma histórica e o Estado contribui para a manutenção das iniquidades, quando não institui políticas públicas que promovam a equidade, reconhecendo as diferentes especificidades étnico-raciais na saúde.

No Brasil especificamente, estudar a sua história significa imergir numa teia de relações sociais demarcadas por estruturas racistas em sua constituição. Isto porque o Brasil é um país que considera sua história iniciada a partir do momento da chegada dos portugueses em suas terras, carrega nessa mesma história três séculos (1550 a 1888) de escravização dos povos africanos, oriundo de um processo brutal de desumanização destes corpos e de suas intelectualidades, atribuindo ao continente africano um estigma de desgraça e de ausência de riquezas materiais e imateriais. A partir deste momento, passa-se a construir uma noção no imaginário coletivo de que a história do negro no mundo se inicia com a escravização. Trata-se da criação de um povo sem história, sem memória, um povo que tem suas raízes ancestrais apagadas: seus corpos foram sequestrados, traficados, humilhados, massacrados, foram separados de suas famílias, Ihes atribuíram novos nomes, nova religião, novo idioma, defenestraram sua dignidade (NASCIMENTO, 2016). Os europeus consideravam-se superiores, atribuindo inferioridade intelectual, cultural, civilizatória a todos os povos não brancos, não europeus, utilizando-se desse discurso para legitimar a sua dominação 
sobre os mesmos. As estigmatizações presentes em tal discurso vinculou-se mais fortemente aos povos negros, isso se deve aos três séculos de escravização de seus corpos e, principalmente, aos aparatos utilizados pelas formas de governo presentes na história do Brasil para manter e reproduzir estes estigmas. Segundo Vaz (2017), o racismo institucional no Brasil foi legitimado pelo Estado que criou a lei anti-vadiagem, a lei anticapoeiragem, que promoveu a prisão de religiosos de matriz africana, reduziu a maior idade penal, enfim, gerou uma política de encarceramento em massa da população negra e, em contrapartida, não the ofereceu condições basilares de cidadania (saúde, moradia, educação, mobilidade urbana, emprego). Pelo contrário, em detrimento de um projeto eugenista de sociedade, foram trazidos imigrantes italianos e asiáticos os quais, mesmo vivendo em cortiços e em situações degradantes, possuíam melhores condições de existência comparados a negritude. Em decorrência disto os corpos negros ainda estão associados à sexualidade aflorada, trabalhos braçais e subservientes, à feiura, à ignorância, à criminalidade. Embora a palavra racismo ainda não existisse no período escravocrata, tendo surgido apenas no século XX, o conjunto de ações dos europeus, no processo das relações sociais, que dão corpo à conceituação do racismo, tal como conhecemos hoje, estavam bem presentes e promoviam todos os tipos de exploração. Esta é a raiz estrutural do racismo institucional, uma política de abandono e apagamento da identidade e da história positiva ancestral da negritude. Esse traço cruel da diáspora africana gera na população negra a aceitabilidade no campo psíquico de uma subalternidade programada, fazendo com que esse povo assuma a sua forjada condição de inferioridade e de negação de direitos sociais elementares (ALBUQUERQUE, 2009).

No que tange a questão da Ciência, enquanto complexo social, esta segue os mesmos padrões hierárquicos estabelecidos socialmente, reproduzindo assim os estigmas e os esquemas de opressões vivenciados pelas "minorias" sociais.

Historicamente a Ciência foi reconhecida com seu nascimento no continente europeu na modernidade, tendo sido negados todos os saberes 
produzidos por povos ancestrais anteriores às civilizações europeias, mas que foram fundamentais para a estruturação do conhecimento greco-romano (MACHADO; LORAS, 2014). Neste sentido, as representações de cientistas reproduzidas em manuais de ciências em geral, é a de homens, cis-gênero, heterossexuais e brancos. Em outros termos, sendo a ciência um espaço de poder a representação de seu desenvolvimento, foi associada a imagem de sujeitos sociais aceitos e hegemônicos. Assim sendo, todos que estavam fora desses padrões, mas que buscavam se vincular ao processo de desenvolvimento do conhecimento científico eram rechaçados, inferiorizados e silenciados.

\section{METODOLOGIA}

Neste trabalho foi realizado um estudo qualitativo considerando as relações étnico-raciais presentes no meio social e científico (OLIVEIRA, 2008). Para isso, optou-se por realizar uma Revisão Sistemática da Literatura sobre a vida e contribuições de alguns cientistas negros e negras do século XX no desenvolvimento da ciência química no âmbito tecnocientífico e histórico. $O$ livro de Carlos Machado, "Ciência, tecnologia e inovação africana e afrodescendente", foi escolhido como base para a realização do trabalho, que foi complementado a partir de buscas em sites de buscas e base de dados de revistas especializadas em questões étnico-raciais.

A realização de todo trabalho acadêmico e/ou científico exige a realização da verificação de trabalhos anteriormente realizados a fim de não produzir replicatas ou dispor tempo buscando respostas que já foram reportadas por outrem. A esta verificação dá-se o nome de Revisão da Literatura ou Revisão Narrativa. Este procedimento, além de ser recomendado para o levantamento da produção científica disponível, possui também, o objetivo de (re)construir redes de pensamentos e conceitos, que auxiliem na articulação dos saberes produzidos por diversas fontes de modo a encontrar novas possibilidades de estudos sobre o tema que se deseja conhecer ou pesquisar no intuito de realizar novas interpretações. Contudo, este método de revisão apresenta um caráter 
descritivo-discursivo. Não é reprodutível e não apresenta elementos para que o trabalho seja repetido, conferindo-lhe características de estudo empírico e inconclusivo (GOMES; CAMINHA, 2014).

Assim, visando complementar os estudos já existentes e fornecer uma fonte confiável de pesquisa com orientações para novas possibilidades de estudos, outras metodologias de pesquisa vêm sendo desenvolvidas e aplicadas; entre elas, a Revisão Sistemática da Literatura (RSL). Segundo Rhoter (2007), uma RSL equivale a uma revisão planejada para responder a uma pergunta específica e utiliza métodos explícitos e sistemáticos para identificar, selecionar e avaliar criticamente os estudos, além de coletar e analisar os dados dos estudos incluídos na revisão. Este método de pesquisa, como os demais, demanda uma questão clara com critérios de seleção bem definidos, de modo a garantir a qualidade dos estudos sintetizados possibilitando sua reprodução por outra pessoa, e uma conclusão que contribua com novas informações baseadas nos resultados da pesquisa realizada. Desta maneira, RSL bem estruturadas podem contribuir para a atualização e construção de novos estudos e exploração de novas áreas de pesquisa.

A RSL pode ser realizada com base em estudos qualitativos ou quantitativos, parâmetro definido pela questão de pesquisa, e os resultados podem ser apresentados na forma de conclusão, análise ou síntese. A produção de uma RSL qualitativa deve garantir: a identificação dos estudos relevantes (ser descritiva), a equivalência entre o que foi registrado e o conteúdo do estudo (ser interpretativa), a credibilidade dos métodos utilizados (ter embasamento teórico) e a aplicabilidade do conhecimento gerado (ser relevante) (GOMES; CAMINHA, 2014).

Devido à escassez de referências e disponibilidade de informações acerca de cientistas negros e negras, no presente trabalho, o livro do autor Carlos Macchado, Ciência, tecnologia e inovação africana e afrodescendente, foi selecionado como base para a pesquisa. Este livro foi escolhido por apresentar um estudo histórico sobre a participação do povo negro nas ciências exatas, biológicas e humanas, comparando a situação 
entre Brasil, EUA, os antigos Reinos Africanos e os 54 países que compõem o continente Africano. Juntamente ao livro, e de modo a complementar as informações biográficas dos e das cientistas, buscou-se informamações acerca da vida e obra dxs Químicxs em sites norte americanos, visto que a bibliografia em língua portuguesa sobre a vida e obra dessxs cientistxs ainda se mostra insuficiente.

\section{QUÍMICXS NEGRXS DO SÉCULO XX: algumas trajetórias}

Realizamos uma revisão de literatura (em mídia impressa e digital) buscando realizar o levantamento da trajetória de químicxs negrxs do século XX (e nesse momento não focamos naqueles brasileiros, visto que estes serão abordados em outro artigo). Neste sentido, trazemos a história e contribuições de oito cientistas negros e negras da área de química: George Washington Carver (1864 - 1943); Alice Augusta Ball (1892 -- 1916); Lloyd Augustus Hall (1894 - 1971); Percy Lavon Julian (1899 - 1975); Lloyd Albert Quaterman (1918 - 1982); Marie Maynard Daly (1921 - 2003); Roscoe L. Koontz (1922 - 1997) e Cheick Anta Diop (1923 - 1986), sendo quase todos norte-americanos, apenas Diop é senegalês mas, formado na Europa, revelando o quanto a história e o desenvolvimento das ciências, em especial das ciências exatas, possui um caráter masculinizado e centrado na capacidade intelectual de povos oriundos ou formados no hemisfério norte do globo.

FIGURA 1 - George Washington Carver (1864 - 1943)

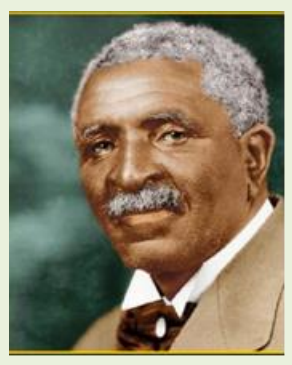

Fonte: [https://lasentinel.net/inventors-and-pioneers.html]. 
Primeiro cientista bioquímico negro dos Estados Unidos da América (EUA), foi o responsável pela implementação da rotação de cultura agrícola na região sul do país. Filho de negros escravizados, foi "adotado" pelos donos da fazenda, que the deram o seu sobrenome, uma vez que, após o período de guerra civil, o regime escravocrata foi abolido em todo o país. Devido ao porte franzino, foi designado a desenvolver trabalhos domésticos e de jardinagem. Neste último, demonstrava e se dedicava à sua vocação, a botânica. Foi alfabetizado em casa, por sua dona, e aos 10 anos de idade passou a frequentar uma escola para afro-americanos, no condado de Newton, sudoeste do Missouri, formando-se no ensino médio aos 25 anos de idade, em Minneapolis - Kansas.

Carver foi contemplado com uma bolsa de estudos para a Universidade Highland no Kansas, mas foi recusado por ser negro. Neste período, vigorava a política segregacionista de Jim Crow, política baseada no princípio "separados, mas iguais". O modelo político aplicado no Sul dos EUA, não permitia que negros e brancos gozassem dos mesmos direitos civis e políticos; situação que se prolongou até meados do Século XX. Diante disso, Carver iniciou estudos na área das artes no Simpson College, em Indianola, lowa, quando foi incentivado por sua professora de artes, Etta Budd, a se dedicar ao que realmente gostava, as plantas. Ele então, transferiu-se para a Faculdade Agrícola do de lowa em 1894, concluindo mestrado em ciências agrícolas, pela mesma instituição, em 1896, aos 33 anos, vindo a se tornar o primeiro professor negro desta Faculdade.

No período que trabalhou no instituto Tuskegee, Alabama, em 1897, se dedicou aos estudos agrícolas e de composição química de cultivo do algodão - atividade agrícola que movimentava a economia da época. Em seus estudos o cientista identificou que o solo, devido aos muitos anos de exploração exclusiva da cultura de algodão, encontrava-se exaurido de nutrientes. Essa exaustão do solo gerou uma crise econômica para os agricultores pobres que viviam nos estados do sul do país, dedicados até então, exclusivamente à cultura do algodão. Durantes seus estudos, ele descobriu que as culturas de amendoim, soja e batata-doce, além de 
crescerem no solo exaurido, possuíam em suas raízes bactérias que promoviam a fixação do nitrogênio ao solo, aumentando, assim seu potencial agrícola. No entanto, por se tratar de culturas sem valor econômico, foi necessário o desenvolvimento de produtos rentáveis a partir desses vegetais, o que motivou o bioquímico a desenvolver 325 produtos a partir do amendoim e 118 produtos a partir da batata-doce, dentre eles 0 queijo, a farinha, corantes e plásticos derivados do amendoim; nitroglicerina, leite, borrachas sintéticas, cremes e sabão a partir da batata-doce. Além desses produtos, ele desenvolveu um novo tipo de algodão, o hibrido Carver.

George Carver foi reconhecido como um dos maiores cientistas botânico do mundo no início do Século e promoveu a manutenção da economia da região sul dos Estados Unidos. Contudo, não patenteou todos os produtos desenvolvidos por ele, havendo registro de apenas três patentes em seu nome. A inexistência de patentes registradas pelo cientista reflete como os feitos e invenções científicos oriundos de estudiosos africanos e afrodescendentes eram suprimidos e suas descobertas atribuídas aos pesquisadores posteriores sem as devidas referências aos precursores dos estudos.

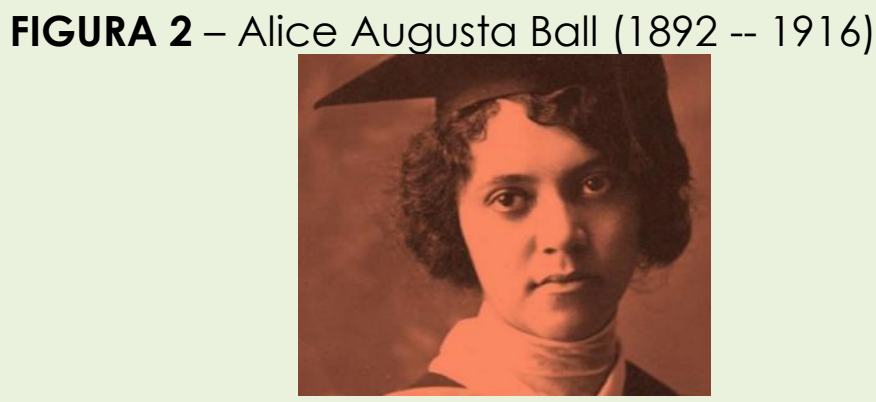

Fonte: [http://aew.org.br/wp-content/uploads/2018/03/El_Pais_Alice_Ball-670x377.jpg].

Nascida em Seattle e de origem nobre, estudou química farmacêutica na universidade de Whashington, obtendo o título de bacharela, em 1912, dois anos depois, em 1914, obteve o título de bacharela em farmácia. Juntamente com seu orientador do curso de farmácia, publicou o artigo 
intitulado "Benzoylations in Ether Solution", um feito inédito na ciência da época, principalmente para as mulheres negras e não negras. Após sua graduação, Ball foi contemplada com bolsas de estudos para a Universidade da Califórnia em Berkeley e para a Universidade do Havaí, optando pela última. Ao se matricular para realizar o mestrado na Universidade do Havaí, tornou-se a primeira mulher e primeira mulher afro americana a se graduar na área de química pela universidade. Seu pioneirismo nesta universidade se estendeu à sua carreira acadêmica, pois, foi a primeira mulher a lecionar como instrutora de química na instituição.

Durante sua pós-graduação, dedicou-se a estudar a composição química e os princípios ativos da Piper methysticum (kava-kava). No entanto, um caso de isolamento de um paciente com lepra a motivou a realizar estudos de composição química e princípios ativos do óleo de Chaulmoogra. Este agente natural era utilizado inicialmente na sua forma "bruta" de forma tópica na medicina oriental. Devido à elevada viscosidade do óleo, as tentativas de ser injetado não foram bem-sucedidas. Outra maneira proposta para o uso era a ingestão, mas devido ao sabor acre e às dores de estômago causadas, muitos pacientes vomitavam logo após a ingestão. Assim, aos 23 anos de idade, Ball conseguiu desenvolver metodologias para isolar os princípios ativos do óleo de Chaulmoogra que pudessem ser facilmente injetáveis e absorvidos de forma eficaz pelo organismo humano.

Contudo, a cientista faleceu por causas até hoje desconhecidas, em 1916, antes de presenciar o sucesso de sua descoberta. Devido a sua morte, a pesquisa iniciada por ela foi continuada pelo presidente da Universidade do Havaí, Arthur L. Dean. Após a conclusão da pesquisa iniciada por Ball, Dean publicou os resultados e patenteou o método como "Método Dean", sem dar os devidos créditos à Alice Ball. Seis anos após sua morte, em 1922, o médico Harry T. Hollmann, que incentivou Ball a desenvolver o tratamento contra a hanseníase, publicou um artigo conferindo o devido crédito à Mestra Alice A. Ball. Mesmo assim, a cientista não teve o devido reconhecimento até o ano 2000,84 anos após sua morte. 
O trabalho desenvolvido por Ball foi fundamental para o tratamento de pacientes com hanseníase sem que estes sofressem isolamento social. $O$ uso do medicamento desenvolvido pela cientista perdurou até o desenvolvimento dos antibióticos na década de 1940. Contudo, em locais mais remotos o "Método Ball" continuou a ser utilizado até 1999.

FIGURA 3 - Lloyd Augustus Hall (1894 - 1971)

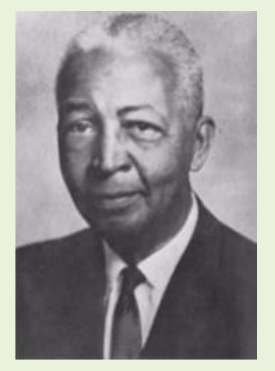

Fonte: [https://www.acs.org/content/acs/en/education/whatischemistry/africanamericans-in-sciences/lloyd-augustus-hall.html] .

Cientista afro-americano nascido após a promulgação da abolição da escravatura, foi responsável pelo aprimoramento de métodos utilizados para a conservação de alimentos, métodos estes, empregados até hoje. Nasceu em Elgin no estado de Illinois, se formou bacharel em Química Farmacêutica pela Northwestern University, em 1914, e obteve seu grau de mestre pela Universidade de Chicago. Após deixar a universidade, Hall foi contratado por uma empresa de engenharia, a Western Electric Company, após uma entrevista por telefone. Contudo, a empresa se recusou a contratá-lo ao descobrir que se tratava de um homem negro.

Durante a Primeira Guerra Mundial foi escalado para atuar como Inspetor Chefe de pós e explosivos, onde, mais uma vez, foi vítima de práticas discriminatórias. Neste caso, foi descriminado pelos militares, motivo que o levou a solicitar transferência da unidade na qual servia ao seu país. No período pós-guerra, Hall trabalhou em diversos laboratórios da área Química até ser contratado pelo Laboratório Griffith em 1925. Neste laboratório ele trabalhou por 34 anos e desenvolveu grande parte de suas inovações na área de engenharia de alimentos. Durante este período o 
cientista aprimorou o uso dos sais cloreto e nitrato de sódio na conservação de carnes, sem que o sabor do alimento fosse afetado.

Outra inovação proposta por Hall foi o uso da glicerina como estabilizante, de modo que o conservante permanecesse dentro da carne, o que revolucionou a indústria de embalagens da época. Além desse procedimento, Hall desenvolveu vários outros processos de conservação de alimento baseados no uso de antioxidantes e esterilização a frio utilizando o óxido de etileno. Esta última técnica, dada a sua eficiência, foi expandida para o uso médico, sendo utilizado na esterilização das equipes médicas e converteu-se em método de esterilização de materiais e equipamentos médicos termossensíveis. Hall registrou 99 patentes, 59 nos EUA e 40 e no exterior e premiado com dois doutorados honorários concedidos pela Virginia State University, Howard University e Tuskegee Institute.

FIGURA 4 - Percy Lavon Julian (1899 - 1975)

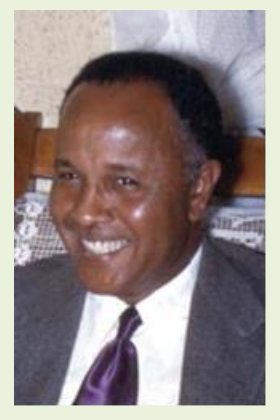

Fonte: [https://www.depauw.edu/news-media/latest-news/details/19008/].

Pioneiro no ramo da Química Orgânica conhecido como Química dos Produtos Naturais, foi também pioneiro no isolamento de substâncias provenientes de plantas para a síntese de medicamentos. Afro-americano, nascido em Montgomery, no estado norte-americano do Alabama, graduou-se em química pela Universidade de DePaw em 1920, conquistou seu PhD pela Universidade de Viena na Áustria em 1931. Ensinou química nas Universidades de Fisk, no West Virginia State College, na Universidade de Howard e, foi diretor de investigação em produtos derivados de soja para a empresa Glidden de Chicago por mais de 20 anos. 
Em seus estudos sobre a síntese da fisostigmina, medicamento utilizado para o tratamento do glaucoma, percebeu progressão da memória em pacientes com Mal de Alzheimer, sendo pioneiro na síntese deste medicamento. Ele foi também um dos pioneiros na síntese química industrial em larga escala dos hormônios humanos (esteroides - progesterona e testosterona) a partir dos esteroides vegetais como o estigmasterol e o sitosterol. Em 1933, sintetizou a cortisona a partir da soja. Seus estudos serviram como base para a síntese de cortisona e outros corticosteroides além da síntese de anticoncepcionais. Com as suas descobertas, Julian propiciou a redução dos custos dos medicamentos sintetizados a partir de substratos extraídos de plantas. As descobertas de Julian promoveram maior acesso da população com menos condições financeiras a esses medicamentos. Suas pesquisas serviram também como base para a síntese de medicamentos para asma, anemia, artrites, hemorróidas, eczemas, alergias, doenças pulmonares crônicas, câncer, glaucoma, prevenção do aborto, tratamentos hormonais, pílulas anticoncepcionais e fortalecimento muscular. Além disso, este cientista sintetizou esteróides intermediários a partir do inhame selvagem mexicano.

Percy L. Julian foi um dos primeiros afro-americanos a se doutorar na área de química e o segundo afro-estadunidense a obter um pósdoutorado. Ele foi um dos maiores cientistas da química do Século XX. E mais uma vez, na história e no ensino das ciências, não há referência ao feito desse cientista. O processo de conservação dos alimentos, bem como a abordagem da descoberta e da síntese de hormônios esteróides, além de não considerarem a maneira processual de como se deu o seu descobrimento, ignora o(s) autor(es) dos estudos que proporcionaram 0 desenvolvimento das metodologias de preparo, aplicações e suas implicações na sociedade. 
FIGURA 5 - Lloyd Albert Quaterman (1918 - 1982)

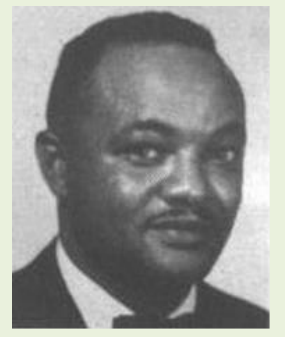

Fonte: [https://www.atomicheritage.org/profile/lloyd-albert-quarterman] .

Natural da Filadélfia, Pensilvania, formou-se como Bacharel em Química pelo St. Augustine's College, Raleigh, Carolina do Norte em 1943. Era considerado um destaque por ser excelente jogador de futebol americano e pela elevada dedicação aos estudos. Devido ao seu bom desempenho nos estudos, logo após receber o diploma de Químico, foi recrutado pelo Departamento de Guerra dos EUA a participar do projeto Manhattan. Esse foi um projeto ultrassecreto do governo dos EUA no período da II Guerra Mundial e tinha como objetivo a produção das bombas atômicas a serem utilizadas durante a guerra. No início da carreira, trabalhou como Químico Junior no projeto. Seu objetivo era isolar o isótopo de urânio-238 (U-238) e desenvolver metodologias para a realização da reação de fissão nuclear do átomo de U-238. Esta reação era essencial para o desenvolvimento da bomba atômica. Quarterman foi reconhecido com um certificado do Departamento de Guerra dos EUA pelo trabalho que foi "essencial para a produção da bomba atômica, contribuindo assim para a conclusão bemsucedida da Segunda Guerra Mundial". Em 1952, o cientista conquistou o título de mestre pela Northwestern University e foi condecorado com um doutorado honorário pelo St. Augustines College, em 1971.

Durante sua carreira como cientista nas áreas de química e física, Quarterman trabalhou juntamente com os físicos Albert Einstein e Enrico Fermi, nos laboratórios da Universidade de Columbia, em Nova York, e no Argonne National Laboratory, em Chicago, Illinois, respectivamente. Os trabalhos desenvolvidos em parceria com esses cientistas possibilitaram o isolamento e manipulação do U-238. Após a destruição causada pelas 
bombas lançadas no Japão as pesquisas acerca do uso da energia nuclear se seguiram. O cientista fez parte da equipe que desenvolveu o primeiro reator de energia nuclear controlada a ser utilizada, em sua totalidade, como fonte de energia.

Deste modo, participou da construção do primeiro reator para o Náutilos, o primeiro submarino do mundo movido a energia nuclear. Além das pesquisas relacionadas à energia nuclear, Quarterman se dedicou ao ramo da espectroscopia química. Neste período, desenvolveu a "janela de diamante", que permitiu ao cientista estudar a fundo a química do fluoreto de hidrogênio, um gás altamente corrosivo. Especialista no elemento químico flúor, ele chegou a sintetizar moléculas, ainda que instáveis, do elemento com os gases até então considerados totalmente inertes nas condições normais de temperatura e pressão - xenônio, argônio e criptônio.

FIGURA 6 - Marie Maynard Daly (1921 - 2003)

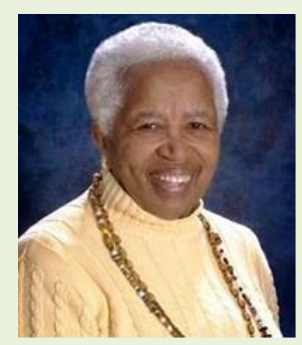

Fonte: [http://mulheresnaciencia-mc.blogspot.com/2014/10/marie-maynard-dalyprimeira-mulher.html].

Bioquímica norte-americana, foi a primeira mulher negra a obter, nos Estados Unidos, um doutorado em Química, pela universidade de Columbia, em 1947. Filha de imigrantes das Índias Britânicas Ocidentais, seu interesse pela ciência foi influenciado por seu pai, que iniciou os estudos para se tornar químico na Cornell University, mas por circunstâncias econômicas foi forçado a deixar os estudos. Marie, desde muito cedo demonstrava interesse pelas ciências, e de acordo com a literatura, seu interesse especial pela obra The Microbe Hunters a fez decidir pela carreira de cientista. A cientista estudou em um colégio destinado exclusivamente para garotas, o Hunter 
College High School, Manhatthan, onde foi encorajada a seguir na carreira de Química. Após concluir o ensino básico, ela se matriculou no Queens College, da Universidade de Nova York, obtendo o bacharelado em Química, com honras, no ano de 1942. Recebeu uma bolsa de estudos para cursar o mestrado na mesma universidade e, para se manter em seus estudos, conseguiu um emprego de auxiliar de laboratório naquela universidade. Após um ano, ela obteve o título de Mestra. No ano seguinte ingressou no programa de doutorado em bioquímica da Universidade de Columbia, onde, depois de três anos de estudo, obteve o doutorado, sendo a primeira mulher negra afro-americana a obter o título de doutora pela universidade.

Começou a lecionar um ano antes da conclusão do doutorado, como instrutora de ciências físicas na Universidade de Howard em Washington, DC - Cargo que só foi conquistado devido à convocação dos homens para atuar na Segunda Guerra Mundial. Ensinou bioquímica na Faculdade de Médicos e Cirurgiões da Universidade de Columbia e em 1960 se tornou professora de bioquímica e medicina da Faculdade de Medicina Albert Einstein, na Universidade Yeshiva. Se dedicou a estudar os aspectos bioquímicos do metabolismo humano e o papel dos rins nesse processo, os efeitos causados no coração e artérias por fatores como envelhecimento, tabagismo, hipertensão e colesterol. Além de sua pesquisa, Daly estava comprometida com o desenvolvimento de programas para aumentar a matrícula de estudantes das minorias em cursos de medicina e pósgraduação em ciências. Então, em 1988, Daly criou uma bolsa de estudos com o objetivo de auxiliar na formação de alunos negros do Queens College com interesse nas áreas de química e física, em memória de seu pai. Em 1999, foi reconhecida pela National Technical Association como uma das 50 mulheres mais influentes nas áreas de Ciência, Engenharia e Tecnologia. 
FIGURA 7 - Roscoe L. Koontz (1922 - 1997)

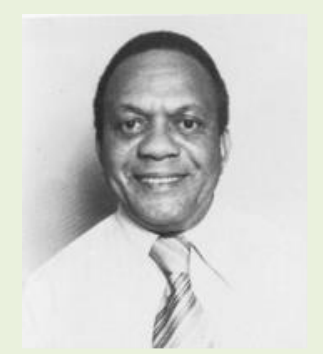

Fonte: [http://www.angelfire.com/wv/jeanwilson/koontz.html].

Nascido na cidade de Saint Lovis, no estado do Missouri, em 1922, Roscoe L. Koontz (1922 - 1997) concluiu seu ensino médio no Vashon High School. Iniciou seus estudos na faculdade Stowes Teachers College, na mesma cidade de origem, mas precisou interrompê-los por três anos devido à convocação pelo exército dos EUA para atuar na Segunda Guerra Mundial. Durante seu período no exército, recebeu treinamento técnico pelo programa de treinamento de pré-engenharia na faculdade West Virginia State College.

Após dispensa do exército, Koontz, retornou ao Estado do Tenessee, onde se formou em Bacharel em Química pela Universidade Estadual do Tenessee. Não foram encontradas muitas informações sobre a atuação desse cientista como químico. Contudo, foram encontradas informações de suas contribuições como físico da saúde, área em ascensão no período final e pós Segunda Guerra Mundial, sendo reconhecida como profissão em 1942. "Juntamente com seus instrutores, os primeiros alunos, como Koontz, originaram muitas das práticas, instrumentação e técnicas de hoje para proteger as pessoas dos perigos da radiação ionizante". Como físico da saúde participou do primeiro programa de formação em Engenharia Atômica voltada à física sanitária, na Universidade de Rochester em 1948.

Durante a pós-graduação, Koontz se dedicou a estudar os efeitos da radiação ionizante, realizando pesquisas sobre problemas de dosimetria de nêutrons, toxicologia de urânio, plutônio e produtos de fissão nuclear. No período que trabalhou na Atomics International, uma empresa no sul da Califórnia, que projeta reatores, ele desenvolveu técnicas e procedimentos 
para medir fluxos de nêutrons usando lâminas de índio radioativo. Ele projetou uma câmera de raios gama pinhole e colimador e ajudou a projetar e fabricar equipamentos automáticos de amostragem de ar e água e dispositivos de medição de atividade radioativa. Esteve envolvido no projeto sobre um sistema de manejo de resíduos nucleares e sódio do Reator do Clinch River em Oak Ridge, no estado do Tennessee. No entanto, o projeto foi cancelado em 1983. O reator não possui aplicação comercial e seu desenvolvimento teve o objetivo de ampliar o uso da energia nuclear dos EUA de dezenas para centenas de anos. Não foram encontradas informações sobre sua aposentadoria e falecimento, o que reforça a importância de se pesquisar de forma mais acurada e produzir bibliografias mais completas de cientistas negros e negras que contribuíram para 0 avanço e desenvolvimento tecnológico e científico da sociedade atual.

FIGURA 8 - Cheikh Anta Diop (1923 - 1986)

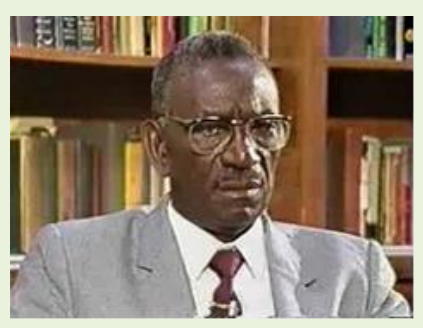

Fonte: [https://ivairs.wordpress.com/2016/03/21/cheikh-anta-diop-a-estrategia-dedesenvolvimento-do-continente-africano/html].

Polímata senegalês formado em Física, Filosofia, Química, Linguística, Economia, Sociologia, História, Egiptologia e Antropologia. Nascido na comunidade Cayłou, região de Diourbel, ao Leste de Dakar, no Senegal, na África sob domínio colonial europeu e submetida a violências de natureza distintas, para além das violências militar, política e econômica. Diop é considerado um dos maiores historiadores e egiptólogo de sua época e pioneiro no que tange aos estudos da historicidade do continente africano, bem como a origem negras dos egípcios, se opondo aos estudiosos de seu tempo que versavam a visão da África como um continente a-histórico e 
atemporal, bem como pregavam a legitimação do negro como um povo inferior intelectual, moral e filosoficamente.

Aos 23 anos de idade foi-lhe concedida uma bolsa de estudos para cursar matemática em Paris, com o interesse inicial de se tornar engenheiro astronáutico. Matriculou-se, no mesmo período, na Faculdade de Filosofia e Letras de Sorbonne, tendo aula com Gastón Bachelard, e obteve seu primeiro grau de licenciado, em filosofia, em 1948. Em seguida, matriculou-se na faculdade de Ciências, obtendo diploma na área de Química em 1950. O cientista possuía uma vida política bastante ativa e além das suas atividades formativas, atuava ativamente na construção de uma identidade positiva da África Negra e participou da criação da Associação de Estudantes Africanos em Paris.

A partir de 1949, o cientista iniciou o que se pode chamar de saga para a obtenção do seu título de doutor, pois precisou enfrentar uma banca composta por homens brancos franceses de visão racista e colonialista. Foi necessário o registro de quatro títulos de tese ("O futuro cultural do pensamento africano", sob a direção do professor Gaston Bachelard - 1949; "Quem eram os egípcios pré-dinásticos" sob o comando do professor Marcel Griaule - 1951; "As áreas do matriarcado e do patriarcado nos tempos antigos" - 1956; e "Estudo comparativo dos sistemas políticos e sociais da Europa e da África, da Antiguidade à formação dos estados modernos" 1957) e a publicação de um livro (produto da tese proposta em 1951), cujos estudos realizados forneceram comprovações científicas que fundamentavam seu argumento da origem negra da civilização que habitou o Egito Antigo, para que fosse possível a titulação em nível de doutorado. A tese aceita pela Universidade de Paris e defendida em 1960, não se referiu à origem e história do Egito no período faraônico. No entanto, demonstrou a preocupação do estudioso com relação ao modelo organizacional das sociedades dos continentes africano e europeu e o modo como elas evoluíram.

Estudioso em linguística e dedicado à cultura e idioma de seu povo, durante sua especialização na Universidade de Paris, Diop dedicou-se 
também a traduzir parte da teoria da relatividade de Einstein para seu idioma nativo, o Woluf. Com isso, além de promover a valorização do idioma nativo de seu país, o cientista promoveu expansão do conhecimento científico para a população do país que fala apenas o seu idioma nativo.

Em 1960, retornou de forma definitiva a seu país natal, e seguiu seu trabalho de reconstituição científica do passado da África e a restauração da consciência histórica do continente. Durante sua atuação como pesquisador e professor na Universidade de Dakar (atualmente denominada Universidade Cheick Anta Diop), iniciou em 1961 a construção de um laboratório para a datação do carbono-14, O IFAN - Instituto Fundamental da África Negra (em francês - Institut de l'Afriquefondamental Noire). As pesquisas dirigidas pelo cientista tinham por objetivo principal, identificar 0 nível de melanina na pele das múmias dos faraós egípcios. Com isso, ele prentendia confirmar a origem negra dos habitantes do Egito Antigo, origem essa, negada, até $\bigcirc$ momento, pelos pesquisadores e historiadores/egiptólogos de seu tempo, todos brancos europeus.

Os resultados de suas pesquisas foram publicados em 1974 no livro intitulado: "A Origem Africana da Civilização: Mito ou Realidade?", obra que reúne evidências arqueológicas e antropológicas sobre a origem da humanidade.

Cheick Anta Diop faleceu em fevereiro de 1986, no Senegal, aos 62 anos de idade, após sofrer infarto. Contudo, deixou um importantíssimo legado e um rico acervo, essencial aos estudos sobre a história do povo africano e sua diáspora. A história e legado desse cientista possui extrema importância não somente para estudos nas áreas de ciências humanas, mas também, nas ciências exatas, pois aponta para a existência de uma historicidade e um legado organizacional e intelectual dos povos oriundos do continente africano e negado aos descendentes negros pelo processo de colonização realizado pelos europeus desde o Século XVI. 


\section{CONSIDERAÇÕES FINAIS}

O surgimento e desenvolvimento da sociedade, conforme as histórias que nos foram contadas, nos fez acreditar que a população negra era/é naturalmente inferior à população branca. Contudo, ao buscarmos um pouco mais a fundo, nos é revelada uma verdade a muito negada, e muito pouco difundida: que $O$ continente africano e a população afrodescendente possuem uma origem, uma história, um legado cultural, filosófico, tecnológico e científico, que muito contribuiu para o desenvolvimento intelectual da humanidade e para a organização das civilizações, cidades e estados tais como o são. A oportunidade de conhecer a história das antigas e atuais civilizações africanas e da população afrodescendente do ponto de vista intelectual, científico e político, confere uma grande possibilidade de mudar a imagem estigmatizada do povo negro dentro da nossa sociedade.

Outro aspecto observado ao realizar o trabalho refere-se à contribuição feminina na área das ciências naturais, em especial na química, ainda ser muito ocultada, principalmente a contribuição de mulheres negras. A busca realizada por cientistas negros e negras revelou $\mathrm{O}$ quanto tais produções são pouco consideradas. Além disso, não foram encontrados resultados referentes a cientistas negros e negras brasileiros, não vivos até o início da produção deste trabalho. Tal resultado revela a importância e necessidade da construção de biografias e valorização das contribuições destxs estudiosxs para o desenvolvimento tecnológico e científico do país.

Assim, de modo a atender à lei 10.639/2003, as histórias e contribuições científicas e tecnológicas dxs cientistas negros e negras devem ser ampliadas e inseridas nos materiais didáticos utilizados no ensino de ciências desde os níveis básicos da educação até os níveis mais elevados de ensino. De maneira a proporcionar uma representatividade real e os jovens negros e negras possam ter perspectivas de alçar voos tão altos quanto os alcançados por essas personalidades científicas. 


\section{REFERÊNCIAS}

ALBUQUERQUE, W. O jogo da dissimulação: Abolição e cidadania negra no Brasil São Paulo: Companhia das Letras, 2009. (319 p.)

BALL, A., pioneira no tratamento da hanseníase, 02/03/2018. Disponível em: <https://brasil.elpais.com/brasil/2018/03/02/ciencia/1520007783_804680.html> Acessado em 26/01/2019.

ALMEIDA, S. L. O que é racismo estrutural? 1. Ed. São Paulo: Letramento, 2018.

Cheick Anta Diop. Disponível em: <http://www.cheikhantadiop.net/>. Acessado em: 02/10/2018.

DIOP, C. A. A origem dos antigos egípcios. IN: MOKHTAR, G. (Org). História Geral da África: A África antiga. São Paulo: Ática/ UNESCO, 1983. Cap. I, 3970.

George Washington Carver. Disponível em:

<https://pt.wikipdia.org/wiki/George_Washington_Carver>. Acessado em: 02/09/2018.

GOMES, I.; CAMINHA, I. Guia para estudos de revisão sistemática: uma opção metodológica para as Ciências do Movimento Humano. Revista Movimento, Porto Alegre, v. 20, n. 01, p. 395-411, jan/mar de 2014.

KAJIBANGA, V. O racismo visto na óptica de quatro autores «lusófonos»: Notas breves a propósito do livro O que é o racismo? Mulemba, Revista Angolana de Ciências Sociais, n. 4, v. 8, 2014.

Lloyod Augustus Hall. Disponível em: <https://en.wikipedia.org/wiki/Lloyd_Hall>. Acessado em: 05.09.2018;

Lloyd Albert Quaterman. Disponível em: <http://www.maricopaaz.gov/web/featured-contributors/1983-lloyd-albert-quarterman-1918-1982manhattan-project-chemist>. Acessado em: 07.09.2018;

Lloyd Albert Quaterman. Disponível em: < https://www.atomicheritage.org/profile/lloyd-albert-quarterman>. Acessado em: 07.09.2018;

Lloyd Albert Quaterman. Disponível em: <http://www.math.buffalo.edu/mad/physics/quaterman_lloyda.html>. Acessado em: 07.09.2018;

Marie Maynard Daly. Disponível em: <http://mulheresnacienciamc.blogspot.com/2014/10/marie-maynard-daly-primeira-mulher.html>. Acessado em: 10. 09. 2018; 
Marie Maynard Daly. Disponível em:

<https://www.sciencehistory.org/historical-profile/marie-maynard-daly>.

Acessado em: 10. 09. 2018.

\section{MACHADO, C.; LORAS, A. Ciência tecnologia e inovação africana e}

afrodescendente. Books, e-book, 2014.

NASCIMENTO, G. X. C. Os perigos dos Negros Brancos: cultura mulata, classe e beleza eugênica no pós-emancipação (EUA, 1900-1920). Revista Brasileira de História. São Paulo, v. 35, n 69, p.155-176, 2015.

NASCIMENTO, A. O genocídio do negro brasileiro: processo de um racismo mascarado. São Paulo: Perspectivas. 2016.

OLIVEIRA, C. L. Um apanhado teórico-conceitual sobre a pesquisa qualitativa: tipos, técnicas e características. Revista Travessias, v. 2, n. 3, 2008.

PACE, A. F.; LIMA, M. O. Racismo Institucional: apontamentos iniciais. Revista do Difere, v. 1, n. 2, dezembro de 2011.

Percy Julian. Disponível em: <https://pt.wikipedia.org/wiki/Percy_Julian>. Acessado em: 05/09/2018.

Roscoe_L._Koontz. Disponível em:

<https://en.wikipedia.org/wiki/Roscoe_L._Koontz>. Acessado em: 15/ 09/2018.

ROTHER, E. T. Revisão sistemática X revisão narrativa. Acta Paulista de

Enfermagem, Escola Paulista de Enfermagem. São Paulo, Brasil v. 20, n. 2, p. vvi, abril-junho, 2007.

SCHUCMAN, L. V. Racismo e Antirracismo: a categoria raça em questão.

Psicologia Política. n. 19. v. 10, 2010.

VAZ, L. Palmares para além do novembro negro. Publicado na Flor de Dendê em 2017. Acessado em 2018-08-14

http://flordedende.com.br/palmares-para-alem-do-novembro-negro/

WITKOP, B. Percy Lavon Julian: 1899-1975. Biographical Memoirs, V. 52.

Washington D. C, The National Academy Press, 1980.

Recebido em: 27 de fevereiro de 2019

Aprovado em: 30 de agosto de 2019 